\title{
Drug utilization pattern and appropriateness of prescription in IPD geriatric patients in a tertiary care teaching hospital
}

\author{
Shuchisuta P. Pathy*, Sachchidanand Pandey, Bhabagrahi Rath, Rinu Rani Dash
}

Department of Pharmacology, VIMSAR, Burla, Sambalpur, Odisha, India

\author{
Received: 20 October 2020 \\ Revised: 22 November 2020 \\ Accepted: 30 November 2020 \\ *Correspondence: \\ Dr. Shuchisuta P. Pathy, \\ Email: shuchi.pathy89@gmail.com
}

Copyright: (C) the author(s), publisher and licensee Medip Academy. This is an open-access article distributed under the terms of the Creative Commons Attribution Non-Commercial License, which permits unrestricted non-commercial use, distribution, and reproduction in any medium, provided the original work is properly cited.

\begin{abstract}
Background: Drug utilization research provides insights into different aspects of drug use and drug prescribing such as pattern, quality, determinants and outcomes of drug use. Polypharmacy is considered to be hazardous for the elderly, because of their greater vulnerability to drugs and multiple drug use. Prescription of potentially inappropriate medications (PIMs) has been found to be a common cause of morbidity and mortality among the geriatric population and has necessitated the creation of criteria for the safe use of medicines among them. Objectives of the study were to assess the drug utilization pattern in geriatric patients and analyse their prescriptions as per the World Health Organization (WHO) core prescribing indicators and STOPP and START criteria.

Methods: An observational, cross-sectional study was conducted from May 2019 to August 2019 in inpatient department of general medicine of VIMSAR, Burla. Prescriptions of $\geq 65$ year patients were collected and documented by active surveillance from the medicine ward.

Results: Majority of the patients were in age group of 65-75. Stroke is the more common comorbidities among geriatric population. Average number of medication per prescription is 5.42 . About $78.74 \%$ of drugs are injectable. The percentage of antibiotics prescribed to patient is $27.75 \%$. Based on STOPP criteria potentially inappropriate medications PIM is $7 \%$ and START criteria PIM is $29 \%$.

Conclusions: Our study suggests that prevalence of polypharmacy was high which is usually unavoidable in geriatric patients and less PIM is suggestive of adherence to WHO core prescribing indicators, and prescription of drugs as per STOPP and START guidelines are indicative of scope for improvement.
\end{abstract}

Keywords: Drug utilization, WHO core prescribing indicator, STOPP and START criteria

\section{INTRODUCTION}

Geriatric population is defined as persons of equal or more than 65 years of age. ${ }^{1}$ Elderly population in India is growing faster than general population. People above 65 years of age are commonly referred to as geriatric population and they would amount to $10.7 \%$ of total population of India by 2021.

Old people have limited regenerative abilities and are more prone to diseases, syndromes, and sickness as compared to other adults. $^{2}$
Many medications need to be used in elderly with special caution because of age-related changes in pharmacokinetics and pharmacodynamics. Hence prescribing to older patients is a unique challenge because premarketing drug trials often exclude geriatric patients and approved doses may not be appropriate for older adults. ${ }^{3}$ The relationship between increased uses of drugs including the prescription medication and elderly is well established. ${ }^{3}$

Drug utilization becomes essential for elderly care, because old age consists of ages nearing or surpassing the 
average life span of human beings. Drug utilization research provides insights into different aspects of drug use and drug prescribing such as pattern of use, quality of use, determinants of use, and outcomes of drug use. ${ }^{4}$ Drug utilization research was defined by World Health Organization (WHO) in 1977 as "the marketing, distribution, prescription and use of drugs in society; with special emphasis on the resulting medical, social and economic consequences." The assessment of drug utilization is important for clinical, educational, and pharmacoeconomic purposes. ${ }^{5}$

Inappropriate medication leads to adverse drug reactions. Different studies have reported rate of occurrence of adverse drug reactions (ADRs) in elderly as high as around $20 \%$ of which almost $50 \%$ are preventable. ${ }^{6}$ Drug use is frequently considered to be hazardous for the elderly, because of the greater vulnerability of the elderly to drugs and to multiple drug use. The purpose of this evidencebased guideline or screening tool is to improve medication management practices for older adults. This suggests that there is a need for uniform criteria for evaluation of appropriateness of prescribing in geriatric patients in particular.

On the other hand, STOPP comprises of 80 indicators pertaining primarily to important drug-drug and drug disease interactions and therapeutic duplication. START incorporates 34 criterion based indicators of prescribing omissions. STOPP/START criteria are considered as the most up to-date set of explicit criteria for evaluating geriatric prescriptions based on drugs prescribed and disease present and require little clinical judgement, thus suitable for use by researchers, students and clinicians.

The present study was conducted to analyse geriatric prescriptions in a tertiary care centre with respect to STOPP/START criteria and WHO core drug prescribing indicators so as to get an idea of pattern of drug prescription in geriatric patients as well as frequency of potentially inappropriate prescriptions. The above information could be used as a baseline to take corrective measures if found necessary.

\section{METHODS}

An observational, cross-sectional study was conducted from May 2019 to August 2019 in inpatient department of general medicine of VIMSAR, Burla. Prescriptions of $\geq 65$ year patients were collected and documented from the medicine ward.

\section{Data collection}

Data was collected from prescription chits, indoor case papers, and also by questioning the patient directly for clarifications wherever required. Pre-structured case record form was used to collect data. Data of demographic parameters like age, gender, was recorded along with disease parameters like diagnosis, concomitant diseases, drugs prescribed, dose of each drug, route of drug administration, frequency of administration of each drug and duration for which the drug was prescribed.

Analysis of prescriptions of enrolled patients was done as follows: WHO drug prescribing indicators such as average number of drugs prescribed per prescription and percentage of prescriptions based on generic/brand names, proportion of prescriptions containing at least one antimicrobial, proportion of prescriptions containing injections and proportion of drugs prescribed from national list of essential medicines was calculated; STOPP criteria were applied for every drug of the prescription individually and marked as PIM whenever found and expressed in term of percentage; similarly START criteria were applied to each prescription to look for omission errors. Proportion of patients subjected to PPOs was calculated and expressed in term of percentage; proportion of patients exposed to potentially inappropriate prescription as a whole was calculated; and to study the potential implications of the above potentially inappropriate prescriptions.

Statistical analysis as descriptive statistics like numbers and percentages were used for data analysis.

\section{Selection criteria}

\section{Criteria for inclusion}

Patients of either sex $\geq 65$ years of age admitted to the department of general medicine.

\section{Criteria for exclusion}

Patients unable to communicate i.e. patients on ventilators, seriously ill patients requiring intensive care unit (ICU) admission.

\section{RESULTS}

Total number of 114 prescriptions from department of general medicine were included in the study and analyzed at the end of four months. The geriatric patient whose prescriptions were studied ranged from 65 years to 95 years. The mean age of these patients was 73.42 , out of which $35.08 \%$ (40) were male and $64.91 \%$ (74) were female.

The average age was 73.42 in which maximum number of patients were of age group 65-70 (68.42\%), followed by $22.8 \%$ were of age group 71-75. 7.01\% were between 7680 and only $1 \%$ patients were $>85$ years.

Highest number of hospitalizations were due to central nervous system diseases i.e. $33.33 \%$, followed by infection i.e. $24.56 \%$. $14.03 \%$ were hospitalized due to cardiovascular diseases. $10.52 \%$ patients were admitted due to gastrointestinal diseases. $5.26 \%$ patients were suffering from respiratory diseases. $12.28 \%$ patients were 
admitted due to miscellaneous causes (polyarthargia, hypoglycemia and dyselectolytemia).

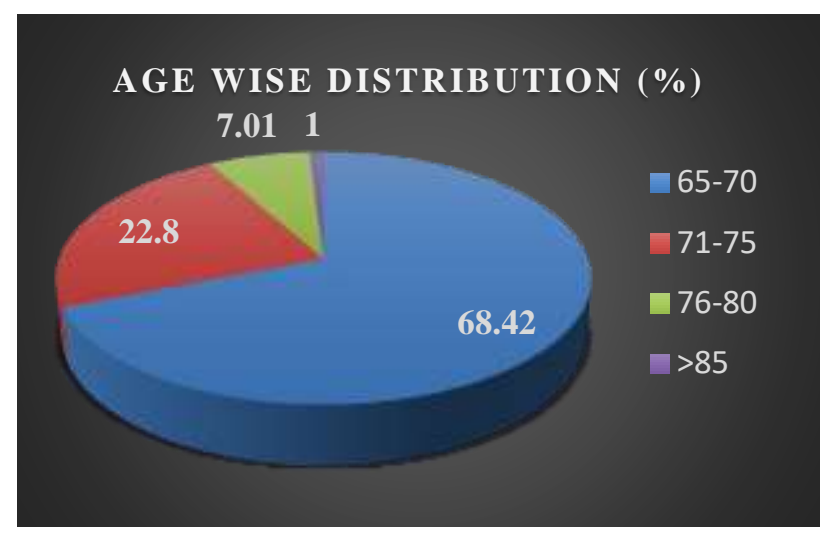

Figure 1: Age wise distribution of patients.

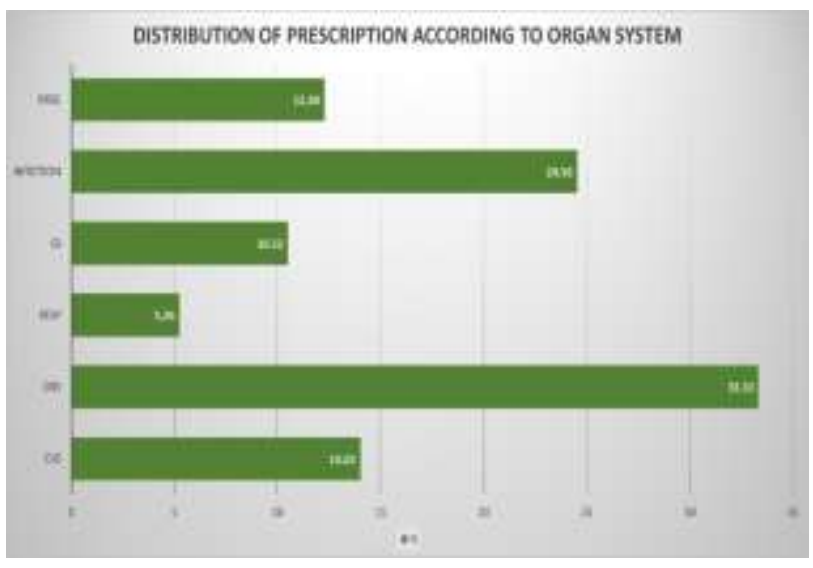

Figure 2: Distribution of prescription according to organ system.

Table 1: WHO core drug use indicator.

\begin{tabular}{|lll|}
\hline SI no. & $\begin{array}{l}\text { WHO core prescription } \\
\text { indicators }\end{array}$ & Percentage (\%) \\
\hline $\mathbf{1}$ & $\begin{array}{l}\text { Average number of drugs } \\
\text { per prescription }\end{array}$ & 5.42 \\
\hline $\mathbf{2}$ & Drugs with generic name & 57.08 \\
\hline $\mathbf{3}$ & Drug from essential list & 90.82 \\
\hline $\mathbf{4}$ & Prescribed antibiotics & 27.75 \\
\hline $\mathbf{5}$ & Prescribed injectable & 78.74 \\
\hline
\end{tabular}

Each prescription contained 5.42 drugs on an average. Based on drug prescription $57.08 \%$ of drugs were prescribed on generic name where as $42.92 \% .90 .82 \%$ of the prescribed drug belongs to drugs prescribed from national list of essential medicines (NLEM). Prescription contained $27.75 \%$ antibiotics on average. $78.74 \%$ of drugs were injectable.

Out of 114 prescription that were analyzed for prescribing errors in elderly as per both STOPP/START criteria, $36.84 \%$ of the prescriptions had at least one error either as STOPP or START criteria.
Patients receiving prescriptions with at least one potentially inappropriate medication prescribed as per STOPP criteria was $7 \%$ while proportion of patients receiving a prescription with potential prescribing omission as per START criteria was $29.82 \%$.

Table 2: Subgroup analysis of PIMs as per START criteria.

\begin{tabular}{|lll|}
\hline $\begin{array}{l}\text { System } \\
\text { category as } \\
\text { per START } \\
\text { criteria }\end{array}$ & $\begin{array}{l}\text { Types of START criteria to } \\
\text { which prescribing error was } \\
\text { attributed }\end{array}$ & $\begin{array}{l}\text { Num- } \\
\text { ber }\end{array}$ \\
\hline $\begin{array}{l}\text { Cardiovasc- } \\
\text { ular system }\end{array}$ & $\begin{array}{l}\text { Statin with known coronary } \\
\text { heart disease }\end{array}$ & 14 \\
\hline & $\begin{array}{l}\text { Beta blocker with ischemic } \\
\text { heart disease }\end{array}$ & 4 \\
\hline $\begin{array}{l}\text { Anticoagula } \\
\text {-nts }\end{array}$ & $\begin{array}{l}\text { Anticoagulant therapy with } \\
\text { documented history of } \\
\text { coronary, cerebral or } \\
\text { peripheral vascular disease }\end{array}$ & 16 \\
\hline Total & & 34 \\
\hline $\begin{array}{l}\text { Percentage } \\
(\%)\end{array}$ & & 29.82 \\
\hline
\end{tabular}

Table 3: Subgroup analysis of PIMs as per STOPP criteria.

\begin{tabular}{|lll|}
\hline $\begin{array}{l}\text { Drug as per } \\
\text { STOPP } \\
\text { criteria }\end{array}$ & $\begin{array}{l}\text { Types of STOPP criteria to } \\
\text { which prescribing error was } \\
\text { attributed }\end{array}$ & $\begin{array}{l}\text { Num- } \\
\text { ber }\end{array}$ \\
\hline $\begin{array}{l}\text { Aspirin plus clopidogrel as } \\
\text { secondary prevention unless } \\
\text { the patient has a coronary } \\
\text { stents inserted in previous } 12\end{array}$ & 6 \\
-nts & $\begin{array}{l}\text { months or concurrent acute } \\
\text { coronary syndrome or has a } \\
\text { high grade symptomatic } \\
\text { carotid arterial stenosis. }\end{array}$ & \\
\hline CNS & $\begin{array}{l}\text { Opioids as } 1^{\text {st }} \text { line therapy for } \\
\text { mild-moderate pain }\end{array}$ & 2 \\
\hline Total & & 8 \\
\hline Percentage & & 7 \\
\hline
\end{tabular}

\section{DISCUSSION}

Geriatric age group is a high risk group population with respect to prescribing patterns. Our study revealed that majority patient were from the age group 65-70 years (68.42\%) followed by $71-75(22.8 \%)$.

The average no of drug per prescription is an important index in drug utilization pattern which is 5.42 which shows polypharmacy while it is similar to the study in Sharma et al i.e. 5.5110 and 5 conducted in another study in Brazil. ${ }^{9,10}$ This confirmed polypharmacy is very common in geriatric population. The reason for polypharmacy is due to multiple comorbidities like hypertension, diabetes, heart failure and their complication. However polypharmacy has its own 
prescribing cascades like adverse drug reaction, drug-drug interaction and drug disease interaction.

Drug prescribed with generic names was found to be $57.08 \%$, in Gosh et al study it was $23 \%$ which is less than our study. ${ }^{11}$ The trend of using brand names was due to attraction on marketing policy which should be discouraged by prescriber. Drugs from essential list was $90.82 \%$.

Prescribed antibiotics was $27.75 \%$ less $\%$ of antibiotics in our study showed because maximum no patients admitted to hospital were having central nervous system (CNS) disorders. Maximum patients were presented with stroke. This is probably due to uncontrolled blood pressure, irregular medication and poor awareness.

Prescribed injectable was $78.74 \%$. As elderly people have more comorbidities their treatment protocol sticks to multiple and complex drug therapy. Therefore chances of ADR and drug-drug interaction are greater.

Analyzing the prescriptions to identify any inappropriate medication as per STOPP criteria and prescribing omission as per START criteria.

The study we have done show $36.84 \%$ PIM. Study conducted in Ireland showed $14 \% .{ }^{12}$ While a study from Australia showed $37.5 \% .^{13}$

As per STOPP criteria use of anticoagulants like both aspirin and clopidogril is restricted to use only in case of secondary prevention rate unless the patient has a coronary stent (s) inserted in the previous 12 months or concurrent acute coronary syndrome or has a high grade symptomatic carotid arterial stenosis but in 6 patients without those above indications prescribers were using both aspirin and clopidogril. Opioids should not be used as 1st line therapy for mild to moderate pain but in 2 patients they have used opioids as 1 st line therapy.

As per START criteria statin should be started with known coronary heart disease but 14 patients were not deviated from this. Use of beta blockers in ischemic heart disease is mandatory but not used in 4 patients which makes the prescription inappropriate. Like this anticoagulants should be used with documented history of coronary, cerebral or peripheral vascular disease but in 16 patients no anticoagulants were prescribed.

Most of the physicians are unaware of screening tools to determine potential inappropriateness in prescription while prescribing to elders.

The explanation for differences in the type of PIM is due to may differ from India due to difference in patient related factors and treatment guidelines. Till now no specific guidelines or screening tools are universally accepted. This study suggests the need for development and implementation of validated screening tools in India by considering population characteristics and treatment guidelines and disease specific factors.

\section{Limitations}

Number of patients in this study is also small and duration of study period is shorter.

\section{CONCLUSION}

Elderly have substantial inter individual variability in health, morbidity, disability and age related changes which make physicians difficult to generalize the prescription. This study provides very useful baseline data and demonstrates the prescribing patterns of drugs in geriatric patient. This type of utilization study may help to improve the quality of health care as well as to prevent further complications in elderly patients occurring due to prescription error. It also aware about appropriate/inappropriate medication to be prescribed and encourage prescribers to follow it strictly for better health care.

\section{ACKNOWLEDGEMENTS}

Authors are thankful to each member who are contributed and extended their support and valuable assistance in planning, conduct and completion of the study.

Funding: No funding sources

Conflict of interest: None declared

Ethical approval: The study was approved by the Institutional Ethics Committee

\section{REFERENCES}

1. Chitra B, Senthilvel N, Sowmya R, Sathyan S and Srisha R. A Study on Prescribing Pattern of Drugs in Geriatrics Using Beers Criteria at a Private Corporate Hospital. Int J Pharm Sci Res. 2015;6(11):4810-25.

2. Starner CI, Gray SL, Guay DRP, Hajjar ER, Handler SM. Geriatrics. In: Dipiro JT, Talbert RL, Yee GC, Matzke GR, Wells BG, Posey LM, editors. Pharmacotherapy A Pathophysiologic Approch. 7th ed. New York: McGraw Hill. 2008;57-66.

3. Cho S, Lau SW, Tandon V. Geriatric drug evaluation: where are we now and where should we be future? Arch Intern Med. 2011;171:937.

4. World Population Ageing 2009, United Nations. New York. The dynamics and consequences of population ageing. Available at: www.un.org/esa/population/.../WPA2009_WorkingP aper.pdf. Accessed on: 25 August 2020.

5. Shah BR, Gajjar MB, Desai VS. Drug utilization pattern among geriatric patients assessed with the anatomical therapeutic chemical classification/defined daily dose system in a rural tertiary care teaching hospital. Int $\mathbf{J}$ Nutr Pharmacol Neurol Dis. 2012;2(3):258-65. 
6. Shah MV, Mehta SD. Drug utilization pattern at medicine O.P.D at tertiary care hospital at Surendranagar. Int J Biomed Adv Res. 2014;5(2):802.

7. Wiffen P, Gill M, Edwards J, Moore A. Adverse drug reactions in hospital patients. Bandolier Extra. 2002. Available at: http://www.bandolier.com. Accessed on: 25 August 2020.

8. Kashyap M, Iqbal MZ. A review of screening tools used for the assessment of appropriateness of prescription's among elderly patients. J Pharm Biomed Sci. 2014;72-9.

9. Sharma N, Advani U, Kulshreshtha S, Parakh R, Bansal A, Sinha RR, et al. Screening of prescriptions in geriatric population in a tertiary care teaching hospital in north India. J Phytopharmacol. 2013;2(5):38-45.

10. Braga TB, Pfaffenbach G, Weiss DP, Barros MB, Bergsten-Mendes G. Point prevalence of drug prescriptions for elderly and non-elderly inpatients in a teaching hospital. Sao Paulo Med J. 2004;122:48-52.

11. Ghosh A, A.K. Das, S. Pramanik and U.K. Saha, 2012. Drug utilization study in patients of acute coronary syndrome on follow-up visits at a tertiary care centre in Kolkata. Asian J. Pharm. Life Sci, 2:155-165.

12. Jafrin AL, Kumar P, Udhayalakshmi T, Jayapriya B, Sawadkar MS. Drug utilization patterns of Geriatric patients admitted in the Medicine Department of a Tertiary Care Hospital. Int J Pharm Life Sci. 2013;4(11).

13. Galvin R, Moriarty F, Cousins G, Cahir C, Motterlini $N$, Bradley $M$, et al. Prevalence of potentially inappropriate prescribing and prescribing omissions in older Irish adults: findings from The Irish Longitu Dinal Study on Ageing study (TILDA). Eur J Clin Pharmacol. 2014;70(5):599-606.

Cite this article as: Pathy SP, Pandey S, Rath B, Dash RR. Drug utilization pattern and appropriateness of prescription in IPD geriatric patients in a tertiary care teaching hospital. Int J Basic Clin Pharmacol 2021;10:55-9. 